\title{
Momento alto do pensamento brasileiro
}

DOI: https://doi.org/10.4322/principios.2675-6609.2021.162.001

E sta edição de Princípios focaliza os artigos e ensaios do dossiê temático "O Iseb e o desenvolvimento nacional”, organizado pelo economista Nilson Araújo de Souza (Ical-Unila) e pelo professor de Filosofia Cristiano Capovilla (UFMA). São trabalhos inéditos resultantes de pesquisas e ensaios teóricos que contribuem para a compreensão do movimento político-intelectual organizado em torno ao Instituto Superior de Estudos Brasileiros (Iseb) a partir da segunda metade da década de 1950. O dossiê ajuda a compreender o contexto histórico em que emerge esse movimento e, principalmente, seu papel como oficina do pensamento nacional-desenvolvimentista.

O Iseb congregou a parcela da intelectualidade que mais se destacava na luta (teórica e prática) pela transformação da realidade brasileira. O ponto de coesão de nomes como Roland Corbisier, Nelson Werneck Sodré, Álvaro Vieira Pinto, Guerreiro Ramos, Anísio Teixeira e Ignácio Rangel, entre outros, era a formulação de um pensamento que buscasse corresponder às necessidades do país e que servisse ao desenvolvimento nacional — ou seja, à superação dos entraves a esse desenvolvimento, à superação da dependência.

Ainda que nem sempre de forma explícita, os intelectuais do Iseb foram responsáveis por fundamentar e sistematizar o pensamento nacional-desenvolvimentista, como também a ideia de revolução brasileira. Destacam-se como características dessa abordagem o controle nacional sobre a economia do país, sobre o Estado e, consequentemente, sobre o investimento público, considerado alavanca do desenvolvimento; a prioridade conferida ao mercado interno, impulsionado pela valorização dos salários, e a necessidade de elaboração de uma ideologia do desenvolvimento. Daí o rancor que os isebianos experimentaram por parte daqueles que se submetiam à integração subordinada e, consequentemente, aos interesses do imperialismo estadunidense. Não à toa, após o golpe de I964, a sede do Iseb, inclusive sua biblioteca, foi destruída.

A questão nacional era, portanto, o centro dessa formulação, donde os termos "nacionalismo" e "nacional-desenvolvimentismo". Algumas polêmicas da época teimam em reaparecer no debate contemporâneo, e isso não ocorre à revelia. Há problemas do país, como sua relação subordinada com os potentados internacionais, que seguem irresolvidos. Persiste, portanto, a luta política e ideológica contra a dependência econômica, política, cultural e tecnológica.

Como toda elaboração teórica consistente, o pensamento do Iseb antecipa tendências, mas ao mesmo tempo condensa os elementos essenciais da realidade. Os intelectuais isebianos anteciparam tendências ao servir de inspiração para as chamadas "reformas de base" 


\section{Os intelectuais do Iseb foram responsáveis por fundamentar e sistematizar o pensamento nacional-desenvolvimentista, como também a ideia de revolução brasileira}

de João Goulart, e condensaram a essência da realidade da época não apenas ao interpretar o programa implementado desde 1930 por Getúlio Vargas, mas também ao sistematizar e aprofundar o pensamento que lhe serviu de fundamento, o nacional-desenvolvimentismo.

Um dos pensadores que mais se destacaram nos trabalhos do Iseb foi o general e historiador Nelson Werneck Sodré, também dirigente do Partido Comunista. Não à toa, quando Helio Jaguaribe, entre 1958 e I959, liderou no Iseb um grupo que tentou conduzir a instituição rumo ao que chamou de "nacionalismo de fins" - que, na verdade, era um "nacionalismo" sem nacionalismo, com importantes concessões ao capital estrangeiro, já iniciadas por JK - , foi Sodré o escalado para ministrar, em março de 1959, a aula inaugural do curso regular do Iseb, que recebeu o título de "Raízes históricas do nacionalismo brasileiro".

Este é um dos textos mais citados na historiografia brasileira, ainda que não suficientemente conhecido e estudado. Essa aula constituiu-se em um dos principais instrumentos na luta de ideias contra o "nacionalismo de fins". Designada "desenvolvimentismo sem nacionalismo" por Sodré, essa formulação de Jaguaribe foi rejeitada, ainda entre 1958 e 1959, pela maioria da intelectualidade do Iseb. A escolha de Nelson Werneck Sodré para realizar a aula inaugural de 1959 reflete a vitória do setor nacionalista sobre o setor que intentava descaracterizar o nacionalismo, e que terminou por sair do Instituto, abraçando crescentemente as teses qualificadas como entreguistas. De formação marxista, Sodré era, dentre os integrantes do Iseb, um dos que achavam que concluir a construção da nação brasileira era um passo insubstituível para a construção do socialismo no país.

Outra aula inaugural, ocorrida três anos antes, em maio de 1956, marcou o início dos cursos do Iseb e cumpriu um papel fundamental para o pensamento isebiano. A aula, cujo título era "Ideologia e desenvolvimento nacional", foi ministrada pelo intelectual de proa que era Álvaro Vieira Pinto. Naquela ocasião ele afirmava: "Sem ideologia do desenvolvimento, não há desenvolvimento nacional". Lembram-se de Lênin? "Sem teoria revolucionária, não há sequer revolução."

A partir dessa tese central, Vieira Pinto formula outras três: I) "a ideologia do desenvolvimento tem necessariamente de ser fenômeno de massa"; 2) "o processo de desenvolvimento é função da consciência das massas"; 3) "a ideologia do desenvolvimento tem de proceder da consciência das massas". Como ficam os teóricos do "populismo", que, na justificativa de sua "teoria", partiam de uma suposta inconsciência das massas como base para a manipulação por parte do líder?

Nessa mesma linha de pensamento segue Roland Corbisier. Filósofo e primeiro diretor-executivo do Iseb, ele avaliava que, se a questão do subdesenvolvimento nacional 
encontrava sua contraproposta prática no desenvolvimento econômico, então o problema da superação da ideia colonial implicava a confecção de um aparato teórico capaz de fazer frente a essa alienação perante a metrópole pensante. A ruptura com a condição de semicolônia em que se encontrava o Brasil implicava, na sua compreensão, não só o desenvolvimento econômico da nação, mas, ao mesmo tempo, uma "conversão do país a ele próprio". Por isso, o esforço no sentido da construção de uma "ideologia ou teoria do desenvolvimento nacional". O desenvolvimento do país era a obra complementar da nossa independência política, ou, dito de outra forma, o país precisava de independência econômica e cultural para completar sua independência política.

Outros pensadores isebianos, com destaque para Guerreiros Ramos e Anísio Teixeira, visitam as páginas desta edição de Princípios, que se configura, dessa forma, como painel - embora sem quaisquer ambições de completude - voltado ao resgate de autores e temas relacionados a um dos momentos altos do pensamento brasileiro.

A edição se completa com artigos inéditos sobre importantes temas contemporâneos. Um deles, sobre temática adjacente à do dossiê, aborda o nacionalismo popular revolucionário a partir da obra do pensador argentino John William Cooke, uma das principais referências do peronismo de esquerda. Dando sequência a seu esforço de tradução de textos relevantes e de grande atualidade, até então indisponíveis em nosso idioma, Princípios publica artigo que expõe uma importante teoria sobre a natureza da economia chinesa. Há ainda trabalhos sobre filosofia do Estado, sobre a realidade dos trabalhadores uberizados e sobre o conceito de vida, discutido à luz da natureza dos vírus - tema que se atualiza em tempos de pandemia.

Boa leitura!

A Comissão Editorial

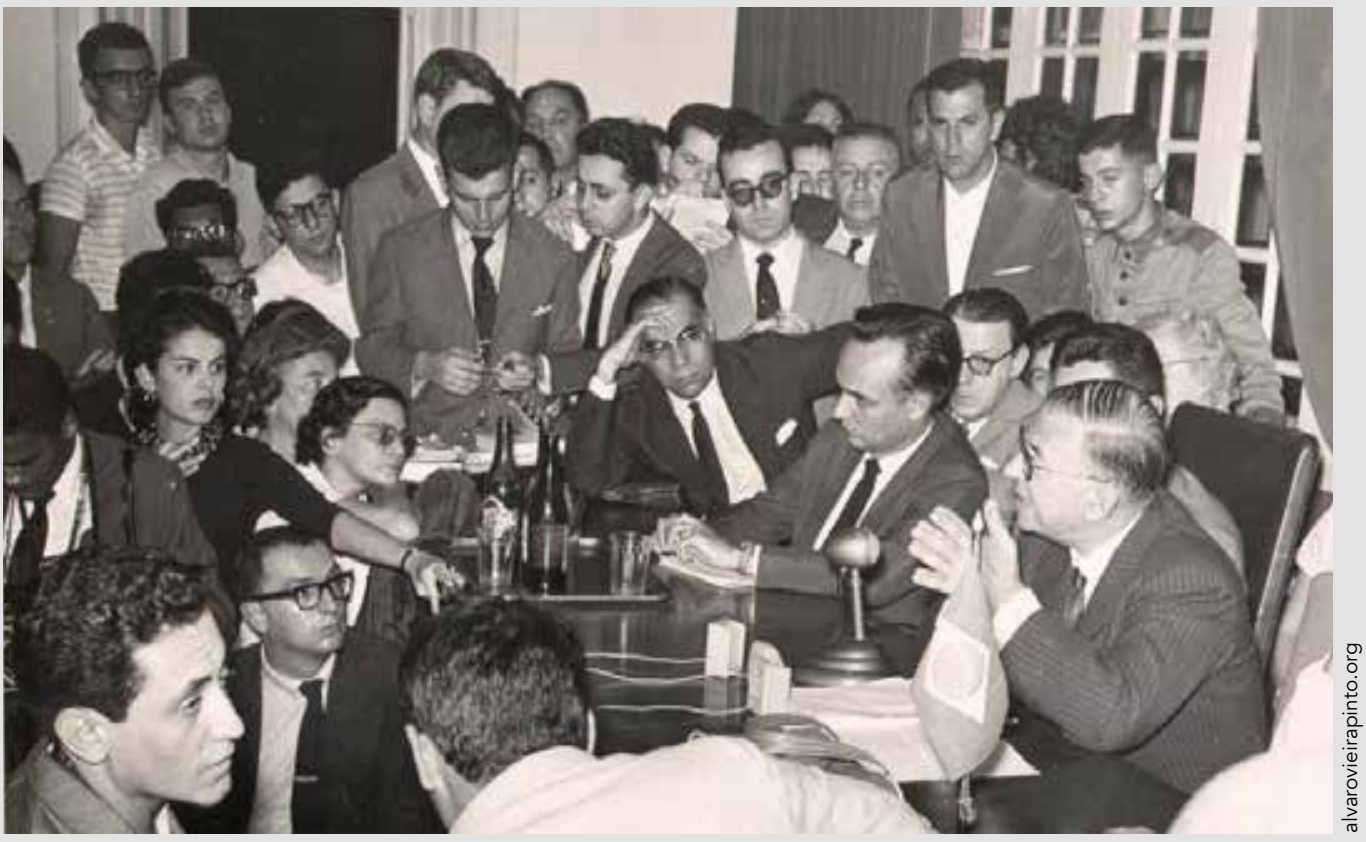

Jean-Paul Sartre (de óculos) faz palestra no Iseb. Compõem a mesa Roland Corbisier (à dir. de Sartre) e Álvaro Vieira Pinto (logo atrás, de óculos). Acervo da família, doado a Fabrício Augusto Souza Gomes 